\title{
The Role of Atmospheric Elements in the Wide Band-Gap Semiconductors Acta Physica Polonica A 136, 916 (2019), ERRATUM
}

\author{
R. JAKIEEA* \\ Institute of Physics, Polish Academy of Sciences, Aleja Lotnikow 32/46, PL-02668 Warsaw, Poland
}

\begin{abstract}
The paper addresses the role of ambient elements $(\mathrm{H}, \mathrm{C}, \mathrm{N}$ and $\mathrm{O}$ ) in the wide-bandgap semiconductor compounds. Their prevalence in the atmosphere imposes limitations not only on the purity of the materials under processing but, also, on the detection and measurement of the content of these species. Specifically, a review of electrical and optical properties, based on the available literature, is presented for: hydrogen in $\mathrm{GaN}, \mathrm{ZnO}$ and $\mathrm{SiC}$, carbon in $\mathrm{GaN}$ and $\mathrm{ZnO}$, nitrogen in $\mathrm{ZnO}$ and $\mathrm{SiC}$ and oxygen in $\mathrm{GaN}$ and $\mathrm{SiC}$. Further, the refinements of the SIMS (Secondary Ions Mass Spectrometry) analytical technique, aiming to improve the sensitivity and detection limit of atmospheric elements, are described in detail. These include the choice of primary beam type and current, type of secondary single or cluster ions, geometry and vacuum conditions. Finally, the evaluated so-called RSF parameters (Relative Sensitivity Factors) are given for each atom-semiconductor pair, converting raw data to the absolute value of concentration.
\end{abstract}

original DOI: 10.12693/APhysPolA.136.916

actual DOI: 10.12693/APhysPolA.137.437

PACS/topics: atmospheric elements, wide bang-gap semiconductors, SIMS

This article was originally published on December 2019 without Refs. [115, 116]. The first paragraph of Subsect. 4.1 (where the references are cited) and the Refs. $[115,116]$ can be found below.

\subsection{Nitrogen properties in $\mathrm{ZnO}$}

The position of nitrogen and oxygen in the Periodic Table, would suggest that $\mathrm{N}$ is the ideal candidate for an acceptor doping of ZnO. Such possibility indeed was demonstrated by Kobayashi in 1983 [112]. However, despite many efforts, a stable and high hole concentration in nitrogen doped $\mathrm{ZnO}$ material was not achieved so far. Even with a dopant concentration as high as $10^{19}$ at $/ \mathrm{cm}^{3}$ in the layer grown by molecular beam epitaxy, the material did not exhibit acceptor conductivity [113]. This was ascribe to a large amount of carrier compensating defects. The hole concentration of $9 \times 10^{16} \mathrm{~cm}^{-3}$ at the nitrogen concentration of $10^{18}-10^{19} \mathrm{at} / \mathrm{cm}^{3}$ in homoepitaxial layers grown by MBE [114] was achieved. Less known Metalorganic Molecular-Beam Epitaxy (MOMBE) method was used to grow $\mathrm{ZnO}: \mathrm{N}$ layers with the nitrogen concentration of $10^{20} \mathrm{at} / \mathrm{cm}^{3}[115]$. Acceptor concentration of $5 \times 10^{16} \mathrm{~cm}^{-3}$ using mercury probe capacitance-voltage measurement was demonstrated, in spite of a high hydrogen concentration over $10^{21}$ at $/ \mathrm{cm}^{3}$. The exceeding of certain nitrogen concentration in the layers grown by MBE method results in the conversion of $p$-type into high-resistive material [116]. A large redshift in the donor-acceptor pair emission was observed in photoluminescence measurements, which was explained by a large compensation of $\mathrm{N}_{\mathrm{O}}$ acceptors by $\left(\mathrm{N}_{2}\right)_{\mathrm{O}}$ donors. Comparison of the influence of nitrogen sources on $\mathrm{N}$ doping in the plasma assisted molecular beam epitaxy (PAMBE) method was given in [117]. With NO as a nitrogen precursor the electrical activity of doping was found superior to the $\mathrm{N}_{2}$. Using this precursor for $\mathrm{ZnO}$ : $\mathrm{N}$ growth the carrier concentration of $1.25 \times 10^{18} \mathrm{~cm}^{-3}$ was achieved with the mobility of $0.5 \mathrm{~cm}^{2} / \mathrm{Vs}$, while $\mathrm{N}_{2}$ precursor led to the formation of the $n$-type layer.

[115] A.B.M.A. Ashrafi, I. Suemune, H. Kumano, S. Tanaka, Jpn. J. Appl. Phys. 41, L1281 (2002)

[116] Shujie Jiao, Y. Lu, Z. Zhang, B. Li, B. Yao, J. Zhang, D. Zhao, D. Shen, X. Fan, J. Appl. Phys. 102, 113509 (2007)

Editors apologize for this error.

*corresponding author; e-mail: jakiela@ifpan.edu.pl 